\title{
PEMIKIRAN AWAL TENTANG KERANGKA DASAR ANALISIS INFRASTRUKTUR PUBLIK BAGI PEMBANGUNAN
}

\author{
Hitapriya Suprayitno1,a \& Ria Asih Aryani Soemitro2,b \\ 1Departemen Teknik Sipil, Institut Teknologi Sepuluh Nopember (ITS), Surabaya \\ Email: asuprayitno.hita@gmail.com \& bsoemitroraa@gmail.com.
}

\begin{abstract}
ABSTRAK
Pembangunan merupakan salah satu nafas bagi kehidupan wilayah atau negara. Telah jelas terlihat bahwa keberadaan Infrastruktur mutlak perlu bagi pembangunan. ITS telah membuka Program Studi Pembangunan. Oleh karena itu penelitian tentang hubungan timbal balik antara infrastruktur publik dengan pembangunan mutlak perlu untuk dikembangkan di ITS, untuk itu diperlukan suatu Kerangka Dasar Analisis. Makalah ini menyampaikan upaya awal untuk menyusun Kerangka Dasar bagi Analisis Hubungan antara Infrastruktur dengan Pembangunan. Kerangka Dasar disusun berdasarkan 4 pemahaman utama: infrtruktur, pembangunan, keterkaitan antara infrastruktur dengan pembangunan dan manajemen aset infrastruktur. Kerangka Dasar Analisis harus didasarkan pada Kebutuhan akan Infrastruktur disesuaikan dengan Kondisi Wilayah dan Program Pembangunan Wilayah; pada Katagori Infrastruktur Publik atau Infrastruktur Swasta; pada Analisis Manfaat dan Biaya; pada Analisis Kelayakan Teknis, Ekonomi dan Sosial; pada Pengelolaan Infrastruktur Berkelanjutan; pada penggolongan Infrastruktur Publik tidak diusahakan dan disusahakan; pada Fungsi Infrastruktur; pada Tipe Bangunan Fisik Infrastruktur; pada Klasifikasi Infrastruktur : baik klasifikasi penanggung jawab, klasifikasi fungsi dan klasifikasi lain
\end{abstract}

Kata kunci: pembangunan, infrastruktur, kerangka dasar analisis, pemikiran awal.

\section{PENDAHULUAN}

Pembangunan merupakan salah satu nafas bagi kehidupan wilayah atau negara. Telah jelas terlihat bahwa keberadaan Infrastruktur mutlak perlu bagi pembangunan. Pembangunan bisa berarti pembangunan suatu wilayah (nasional, provinis, kabupaten atau kota), pembangunan suatu sektor kehidupan (pendidikan, ekonomi, industri, pertanian, enerji, dan sebagainya). Infrastruktur dan fasilitas publik merupakan bagian integral dari pembangunan-pembangunan tersebut. Dengan demikian infrastruktur \& fasilitas publik harus diadakan dan dikelola dengan baik. Untuk itu pengetahuan tentang infrastruktur pembangunan perlu untuk didalami dan dikembangkan.

Institut Teknologi Sepuluh Nopember (ITS) harus mampu untuk berpartisipasi dalam Pnedidikan dan Pengembangan Ilmu Pengetahuan Studi Pembangunan dan Infrastruktur Pembangunan. Unutk itu ITS telah membuka Program Studi Pembangunan dan Program Magister Manajemen Aset Infrastruktur. Oleh karena itu penelitian tentang hubungan timbal balik antara infrastruktur dengan pembangunan mutlak perlu untuk dikembangkan di ITS. Untuk itu diperlukan suatu Kerangka Dasar bagi Analisis Keterkaitan Antara Infrastruktur dengan Pembangunan. Makalah ini menyampaikan upaya awal untuk menyusun Kerangka Dasar bagi Analisis Keterkaitan antara Infrastruktur dengan Pembangunan.

\section{METODE PENELITIAN}

Makalah ini merupakan hasil dari suatu penelitian Penyusunan Konsep berbasis Analisis Review. Penelitian ini mengikuti urutan pemikiran sebagai berikut : pemikiran latar belakang, penentuan tujuan penelitian, kajian pustaka, penyusunan kerangka, dan diakhiri dengan penutup.

\section{BEBERAPA KAJIAN PUSTAKA PENTING}

Kajian Pustaka ini terutama diarahkan untuk mengumpulkan beberapa catatan pengertian dasar tentang Pembangunan, Infrastruktur, dan Manajemen Aset Infrastruktur \& Fasilitas. 
Kata Pembangunan bisa diartikan dan didefinisikan dengan rumusan yang berbeda-beda, dalam berbagai aspek yang berbeda-beda serta komponen pembangunan bermacam-macam. Akan tetapi secara umum Pembangunan selalu mengandung konotasi membuat sesuatu menjadi lebih baik dengan menggunakan program yang direncanakan dan dilaksanakan dengan baik. Secara umum kata Pembangunan banyak dikaitkan dengan Pembangunan Ekonomi \{(Abidin, 2017); (Adisasmita, 2014); (AU\&NEPAD, 2011); (Prud'homme, 2004); (Reyes, 2001); (Shareia, 2015); (Wikipedia, 2018b)\}. Uraian ini sudah dianggap cukup untuk penulisan makalah ini. Sudah barang tentu pengertian ini harus dijabarkan lebih lanjut untuk pendalaman lanjutan.

Infrastruktur sering diklasifikasikan sebagai "infrastruktur keras" dan "infrastruktur lunak". Infrastruktur Keras adalah bangunan fisik buatan manusia yang dibutuhkan bagi kehidupan wilayah. Contoh Infrastruktur Keras dasar antara lain : infrastruktur jalan, infrastruktur jembatan, infrastruktur sanitasi, infrastruktur penyediaan air bersih, infrastruktur enerji listrik, infrastruktur distribusi bahan bakar, infrastruktur telekomunikasi, dan infrastruktur yang lain. Infrastruktur Keras sering dibedakankan kedalam : infrastruktur sipil dan infrastruktur militer, infrastruktur ekonomi dan infrastruktur sosial, infrastruktur publik dan infrastruktur swasta (Wikipedia, 2018b). Untuk sementara waktu ini, uraian tentang infrastruktur tersebut masih dianggap cukup bagi penulisan makalah ini. Uraian tersebut tentu masih dikembangkan sesuai dengan keperluan kedalaman dan kelauasan Pemikiran.

Keterkaitan antra Infrastruktur dengan Pembangunan Ekonomi secara singkat, global dan mendasar bisa disampaikan sebagai berikut. Aktivitas Ekonomi dilkukan sektor swasta atau oleh Badan Usaha Milik Negara atau Daerah (BUMN/D) untuk aktivitas tertentu yang strategis atau masyarakat belum mampu melakukannya padahal sangat diperlukan. Dengan demikian fungsi Infrastruktur dalam Pembgunan Ekonomi bisa bersifat Prasyarat bagi terjadinya Aktivitas Ekonomi, bersifat Prasyarat bagi lancarnya Aktivitas Ekonomi dan sebagai Katalisator bagi Pertumbuhan dan Kelancran Aktivitas Ekonomi. (Abidin, 2017); (Adisasmita, 2014); (AU\&NEPAD, 2011); (Prud'homme, 2004); (Shareia, 2015); (Wikipedia, 2018a); (Wikipedia, 2018b). Uraian mengenai keterkaitan antara Infrastruktur dan Pembngunan Ekonomi dirasa sudah mencukupi unutk Pemikiran Awal ini. Uraian diatas tentu masih diperdalam lebih lanjut sesuai dengan kedalaman dan keluasan Pemikiran.

Manajemen Aset Infrastruktur \& Fasilitas adalah suatu program dan pengetahuan untuk mengelola dengan baik suatu infrastruktur dan/atau fasilitas, agar infrastruktur dan/atau fasilitas bisa berfungsi dengan baik secara berkelanjutan, ekonomi, efisien dan efektif, serta memenuhi prinsip "green" (berkelanjutan bagi aspek ekonomi, aspek sosial dan aspek lingkungan) (Suprayitno, H. \& Soemitro, 2018). Uraian mengenai Manajemen Aset Infrastruktur \& Fasilitas dianggap sudah mencukupi bagi Pemikiran Awal ini. Uraian tersebut masih diperdalam dan diperluas sesuai dengan kedalaman dan keluasan Pemikiran yang sedang dilakukan.

\section{PENYUSUNAN KERANGKA DASAR ANALISIS}

\section{Tujuan Penyusunan Kerangka}

Penyusunan Kerangka ini adalah suatu upaya untuk mendapatkan suatu pedoman bagi tinjauan atau analisis Infrastruktur dan Pembnagunan, agar Tinjauan dan Analisis tersebut bisa bersifat sistematis, benar dan lengkap.

\section{Langkah Penyusunan Kerangka}

Penyusunan Kerangka Analisis ini telah dilakukan dengan mengikuti tahapan langkah penyusunan sebagai berikut: perumusan arti kata pembangunan, perumusan arti kata infrastruktur, perumusan keterkaitan antara infrastruktur dan pembangunan, dan diakhiri dengan penyusunan kerangka analisa. Penyusunan harus dilakukan dengan urutan seperti diatas karena memang arti pembangunan dan infrastruktur itu luas. Dimensi pembangunan dan infrastruktur itu sangat bervarisi. Pengertian Dasar Pembangunan 
Dalam Penyusunan Kerangka ini, pengertian dasar tentang pengertian Pemangunan disusun secara sangat sederhana : "Pembangunan adalah tindakan untuk membuat sesuatu menjadi lebih baik, dengan terencana". Dalam makalah ini yang dimaksud dengan "sesuatu" adalah "kehidupan masyarakat yang hidup dalam lingkungan sosial dan lingkungan alam, dan saling terkait satu dengan yang lain". Tujuan Dasar Pembangunan adalah "mensejahterakan masyarakat jasmani dan rohani dalam lingkungan hidup yang baik, masyarakat yang adil makmur". Hal ini bisa dilihat dalam berbagai sektor kehidupan masyarakat.

Berbagai Sektor Kehidupan Masyarakat bisa dilihat dari kebutuhan yang ada dalam perjalanan hidup seseorang. Secara umum kehidupan seseorang bisa diurutkan secara sederhana sebagai berikut : lahir, balita, sekolah, bekerja, berumah tangga, meninggal. Dalam urutan kehidupan tersebut sesorang membutuhkan : layanan kesehatan, layanan pengelolaan balita, layanan pendidikan, layanan pekerjaan, layanan kebutuhan dasar hidup sehari-hari, layanan peribadatan, layanan hiburan, layanan olah raga dan layanan meninggal dengan baik.

Uraian diatas ini bisa digambarkan pada Tabel 1 dan Gambar 1 sebagai berikut.

Tabel 1 Kebutuhan Layanan Publik bagi Kehidupan Seseorang Sepanjang Hidupnya

\begin{tabular}{|c|c|c|c|c|c|c|c|}
\hline & & \multicolumn{6}{|c|}{ rumah tangga } \\
\hline USIA & & lahir & balita & sekolah/kuliah & bekerja & pensiun & meninggal \\
\hline \multirow{10}{*}{$\begin{array}{l}\text { LAYANAN } \\
\text { PUBLIK }\end{array}$} & kesehatan & 0 & 0 & 0 & 0 & 0 & \\
\hline & sistem PAUD & & 0 & & & & \\
\hline & pendidikan & & & 0 & 0 & & \\
\hline & usaha & & & & 0 & & \\
\hline & sistem pensiun & & & & & 0 & \\
\hline & pemakaman & & & & & & 0 \\
\hline & olah raga & & o & 0 & o & 0 & \\
\hline & hiburan & & 0 & 0 & 0 & 0 & \\
\hline & belanja & 0 & 0 & 0 & o & 0 & \\
\hline & perumahan & 0 & 0 & 0 & 0 & 0 & \\
\hline
\end{tabular}

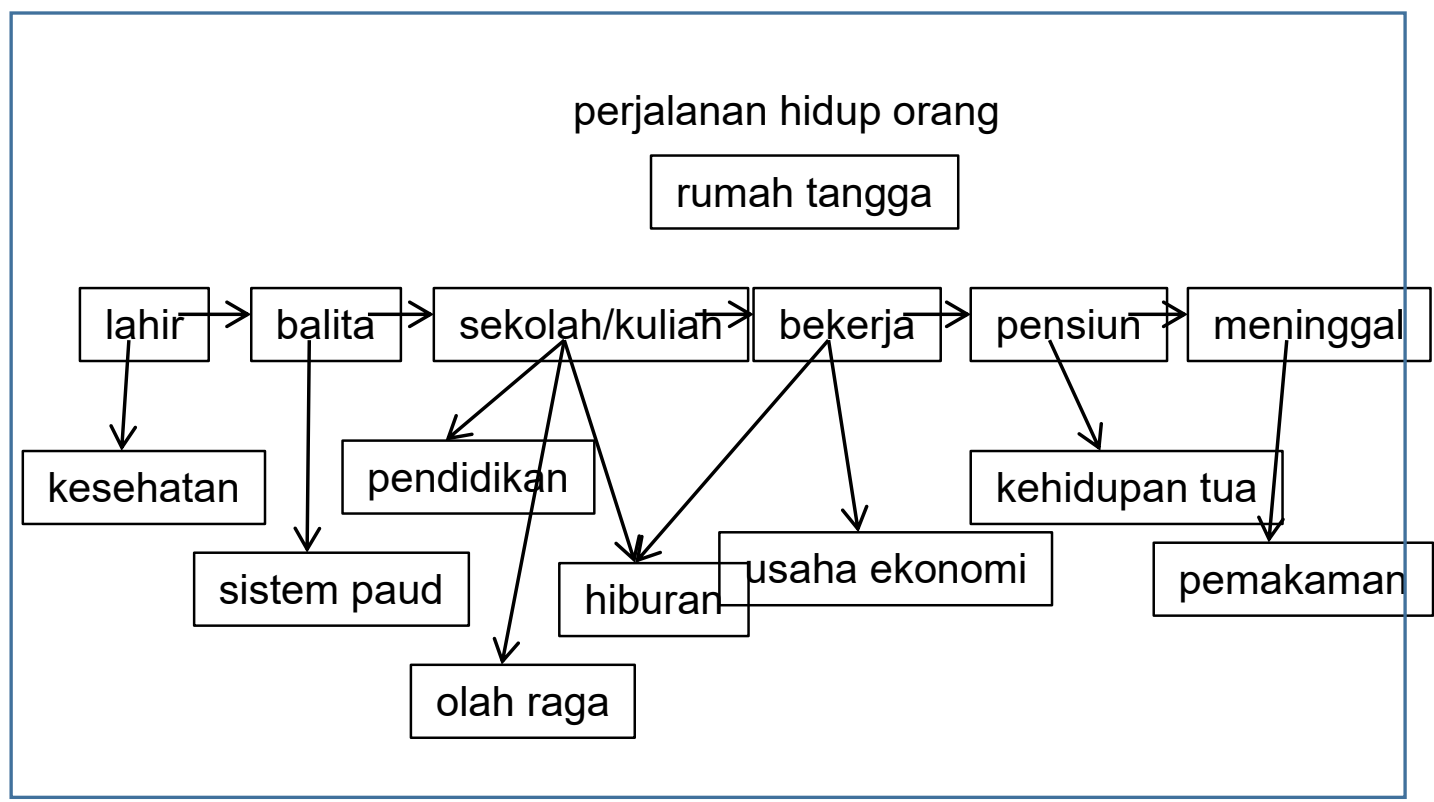

Gambar 1 Diagram Kebutuhan Layanan Publik sepanjang Kehidupan Seseorang

Layanan pekerjaan merupakan aktivitas ekonomi, yang merupakan tulang punggung utama bagi pembangunan ekonomi suatu wilayah atau negara. Pembangunan Ekonomi berarti suatu langkah untuk membuat kondisi ekonomi menjadi lebih baik. Aktivitas ekonomi harus ditinjau kedalam beberpa sektor. Tujuan utama pembangunan ekonomi bisa dinyatakan sebagai berikut :

- Ketahanan ekonomi

- Pertumbuhan ekonomi 
- Pemerataan ekonomi

- Penciptaan lapangan pekerjaan

- Keberlanjutan konidisi ekonomi yang baik.

\section{Pengertian Dasar Infrastruktur}

Infrastruktur adalah suatu bangunan fisik buatan manusia yang dibutuhkan bagi kehidupan wilayah atau suatu kehidupn sektor tertentu. Menyebut infrastruktur harus disertai dengan kata fasilitas, karena kebutuhan akan sekelompok infrastruktur bisa disebut sebagai suatu fasilitas, misal fasilitas olah raga, fasilitas pendidikan, dan yang lain. Infrastruktur diadakan untuk menjalankan fungsi tertentu yang dibutuhkan oleh kehidupan wilayah. Infrastruktur banyak sekali jenisnya, antar lain misalnya : fasilitas perumahan, fasilitas kesehatan, fasilitas pendidikan, fasilitas tempat kerja, fasilitas transportasi, fasilitas telekomunikasi, infrastruktur enerji, fasilitas hiburan, fasilitas olah raga, dan yang lain. Setiap jenis infrastruktur mempunyai fungsi dan karkteristik masing-masing yang berbeda-beda.

Infrastruktur \& Fasilitas Publik dan Pembangunan Ekonomi

Infrastruktur merupakan bagian tak terpisahkan dari Pembangunan Ekonomi, bahkan Infrastruktur merupakan prasyarat utama bagi terjadinya Pembungan Ekonomi. Aktivitas ekonomi tidak bisa berjalan kalau tidak ada infrastruktur.

Aktivitas Ekonomi Primer, misalnya penanaman kebutuhan pokok manusia padi, membutuhkan jaringan irigasi untuk mengairi sawah; jaringan jalan untuk menjual hasil padinya; serta fasilitas perumahan bagi hidupnya para petani. Aktivitas Ekonomi Sekunder, misalnya industri pembuatan kebutuhan pokok kain, membutuhkan fasilitas pabrik, jaringan jalan untuk mendatangkan bahan baku dan memasarkan produksi kain. Sistem produksi membutuhkan fasilitas enerji listrik, fasilitas penyediaan air bersih, fasilitas sistem sanitasi, fasilitas sistem telekomunikasi, fasilitas sistem perbankan. Pabrik juga membutuhkan pekerja unutk bekerja dan pegawai membutuhkan fasilitas perumaham dengan kelengkapannya. Aktivitas Ekonomi Tersier, misalnya perdagangan kebutuhan pokok, membutuhkan bangunan pasar untuk mempertemukan penjual dan pembeli, membutuhkan pergudangan, membutuhkan jaringan jalan untuk mengangkut barang.

\section{Aspek Kebutuhan dan Penyediaan Infrastruktur Publik}

Di dalam keberadaan Infrastruktur Publik secara alamiah terjadi hukum Kebutuhan dan Penyediaan. Hukum ini didalam Ilmu Ekonomi disebut sebagai Hukum Supply-Demand. Hanya mekanisme yang terjadi agak berbeda antara Hukum Supply-Demand pasar ekonomi swasta dengan Keberadaan Infrastruktur Publik. Penyediaan Infrastruktur harus dilaksanakan karena dipicu oleh adanya Kebutuhan Layanan. Fenomena ini secara ringkas digambarkan pada Tabel 2 sebagai berikut.

Tabel 2 Aspek Kebutuhan dan Penyediaan Infrastruktur. 


\begin{tabular}{|c|c|c|c|}
\hline \multicolumn{2}{|c|}{ SISTEM INFRASTRUKTUR } & Jalan & Listrik \\
\hline \multirow{4}{*}{ Kebutuhan } & Geografi & & \\
\cline { 2 - 4 } & Tata Ruang & & \\
\cline { 2 - 4 } & Sistem Aktivitas & & Kebutuhan Listrik \\
\cline { 2 - 4 } & Kebutuhan Layanan & Perjalanan & Beban Listrik \\
\hline \multirow{4}{*}{ Penyediaan } & Pemakaian Infrastruktur & Lalu Lintas & \\
\cline { 2 - 4 } & Infrastruktur & Jaringan Jalan & Jaringan Listrik \\
\cline { 2 - 4 } & Sistem Jaringan Infrastruktur & & \\
\cline { 2 - 4 } & Tata Ruang & & \\
\cline { 2 - 4 } & Geografi & & \\
\hline
\end{tabular}

Aspek Ekonomi dan Finansial Infrastruktur

Di dalam Fenomena Keberadaan (Kebutuhan dan Penyediaan) Infrastruktur Publik secara alamiah mengandung fenomena Aspek Ekonomi dan Finansial. Aspek ini mempunyai tiga fenomena utama yang harus ditinjau :

- Aspek Karakteristik Finansial Penyediaan suatu Infrastruktur Publik

- Aspek Manfaat-Biaya Ekonomi Penyediaan Infrastruktur Publik

- Aspek Ketersediaan Dana Publik bagi Penyediaan Infrastruktur Publik

- Aspek Karakteristik Layanan Infrastruktur dalam hal bisa berbayar dan tidak bisa berbayar Aspek Keruangan dan Lingkungan

Infrastruktur harus serasi dan mampu menunjang aspek keruangan, serta tidak merusak lingkungan atau harus bisa menjaga kondisi lingkungan. Aspek Keruangan bisa dilihat dengan p[andangan sebagai berikut. Tugas Infrastruktur adalah melayani Kehidupan Wilayah. Aktivitas Wilayah harus ditata secara Keruangan. Aktivitas-aktivitas tertentu harus dijauhkan atau didekatkan satu dengan yang lain. Jadi, Infrastruktur harus ditata secara Keruangan. Aspek Lingkungan bisa dilihat dengan pandangan sebagai berikut. Infrastruktur memberi dampak penurunan Kualitas Lingkungan, Infrastruktur juga bisa merupakan bagian untuk mencegah Bencana Lingkungan atau untuk menjaga agar Kualitas Lingkungan tetap terjaga.

\section{Aspek Manajemen Aset Infrastruktur \& Fasilitas}

MAI\&F adalah seluruh program, tindakan dan pengetahuan untuk mengelola I\&F secara baik. Tujuan mengelola disini adalah menjaga agar infrastruktur tersedia dalam jumlah cukup, selalu berada dalam kondisi baik dan selalu bisa berfungsi dengan baik. Kesemuanya terjadi secara berkesinambunagan, ekonomis, efisien, efektif dan bersifat green (sosial, ekonomi dan lingkungan).

\section{Kerangka Dasar Analisis Infrastruktur \& Fasilitas dan Pembangunan}

Berdasarkan uraian mengenai infrastruktur dan pembangunan diatas, untuk sementara ini Pengembangan Penelitian dalam bidang Infrastruktur Pembangunan bisa diarahkan unutk menjawab beberapa pertanyaan utama sebagai berikut :

- Aspek Pembangunan Ekonomi dan Sosial

- Aspeki Golongan, Tipe, Klas dan Karakteristik Infrastruktur

- Aspek Kebutuhan dan Penyediaan Infrastruktur Publik

- Aspek Ekonomi dan Finansial Penyediaan Infrastruktur

- Aspek Keruangan dan Lingkungan Infrastruktur

- Aspek Manajemen Aset Infrastruktur \& Fasilitas

- Aspek Metode dan Alat Analisis bagi Analisis, Evaluasi, Prediksi Kebutuhan serta Pengambilan Keputusan

\section{PENUTUP}

Penelitian telah berhasil diselesaikan dengan baik. Pandangan singkat menyeluruh telah berhasil disusun. Penelitian ini menghasilkan beberapa kesimpulan pokok yang dituliskan sebagai berikut. 
- Pembangunan adalah tindakan unutk membuat kehidupan menjadi lebih baik baik dengan terencana. Didalamnya terdapat dimensi kehidupan ekonomi dan sosial, didalam suatu sistem wilayah.

- Infrastruktur merupakan bagian integral dari Pembangunan. Infrastruktur terdiri dari berbagai sektor, misal : infrastruktur perumahan, infrastruktur kesehatan, infrastruktur pendidikan, infrastruktur pertanian, infrastruktur industri, infratsruktur transportasi, infrastruktur enerji, dan lain sebagainya.

- Tinjauan Sistem Infrastruktur harus dilihat dari Aspek Pembangunan, Aspek Tipologi \& Krakteristik Infrastruktur, Aspek Kebutuhan dan Penyediaan Infrastruktur, Aspek Ekonomi dan Finansial Infrastruktur, Aspek Keruangan dan Lingkungan Infrastruktur, Aspek Pengelolaan Integral Infrastruktur, Aspek Metoda dan Alat Analisis.

- Kerangka Dasar Analisis Infrastruktur diarahkan untuk mendalami seluruh Aspek Infrastruktur diatas.

Penelitian ini seyogyanya diteruskan kearah penelitian tentang : pembangunan : definisi, komponen, tujuan, ukuran keberhasilan; infrastruktur : fungsi, bentuk, klasifikasi, karakteristik, taksonomi; fungsi infrastruktur bagi kehidupan wilayah; aspek ekonomi infrastruktur; dan topik penelitian yang lain.

Catatan : Makalah ini dipresentasikan pada Semateksos3 ITS, disusun dalam rangka Pengembangan Penelitian Infrastruktur bagi Pembangunan di ITS.

\section{DAFTAR PUSTAKA}

Abidin, T. Z. (2017). Analisis Pertumbuhan Ekonomi Dan Pengembangan Sektor Potensial Di Kabupaten Asahan. QE Jurnal, 02(01), 19-33.

Adisasmita, R. (2014). Pengembangan Wilayah: Konsep dan Teori. Yogyakarta: Graha Ilmu.

AU\&NEPAD. (2011). "Le Developpement Infrastructures Comme Agent Catalyseur de la Croissance Economique en Afrique". In 17eme Forum le Partenariat avec l'Afrique (FPA). Addis-Abeba.

Prud'homme, R. (2004). "Infrastructure and Development". , , . In ABCDE - Annual Bank Conference on Development Economics. Washington.

Reyes, G. E. (2001). "Four Main Theories of Development : Modernization, Dependency, WordSyatem nd Globalization". In Nomadas. Revista Critica de Ciencias Sociales y Juridicas (Vol. 04). Madrid.

Shareia, B. F. (2015). "Theories of Development". International Journal of Language and Linguistics, 2(1).

Suprayitno, H. \& Soemitro, R. A. A. (2018). Preliminary Reflexion on Basic Principle of Infrastructure Asset Management. Jurnal Manajemen Aset Infrastruktur \& Fasilitas, 2(1), 1-9.

Wikipedia. (2018a). Development. Retrieved March 3, 2018, from http://en.wikipedia.org/wiki/Development

Wikipedia. (2018b). Infrastructure. Retrieved August 19, 2018, from

http://en.wikipedia.org/wiki/Infrastructure 